\title{
28 Research Square \\ Ionomic and metabolic responses to drought stress in elite wheat seedlings under two phosphorus levels
}

Chunyan Li ( $\square$ lichunyan82@aliyun.com )

Shihezi University

Zhang Xiangchi

Shihezi University

Li Chao

Shihezi University College of Agriculture

Wan Wen

Shihezi University College of Agriculture

Li Cheng

Shihezi University College of Agriculture

Research article

Keywords: wheat, phosphorus, drought stress, growth, elements, metabolites

Posted Date: February 1st, 2021

DOI: https://doi.org/10.21203/rs.3.rs-191827/v1

License: (a) (1) This work is licensed under a Creative Commons Attribution 4.0 International License. Read Full License 


\section{Abstract \\ Background}

Wheat (Triticum aestivum L.) is the main food crop in the worldwide. Low soil phosphorus levels and drought conditions are important constraints for wheat production in most of the areas where wheat is grown. In this study, the analysis of mineral elements and metabolites were used to investigate the ionomic and metabolic responses to drought stress of wheat plants cultured by low phosphorus (LP) and conventional phosphorus (CP) supply, respectively.

\section{Results}

We found that the wheat plants subjected to LP treatment had denser roots, and the total root volume was significantly higher than that under the CP treatment. The roots cultured by two phosphorus levels underwent the process of programmed cell death under drought stress, however, the genomic DNA degradation level of the roots in LP was significantly weaker than that in CP after rehydration for $3 \mathrm{~d}$. The analysis of mineral elements and metabolites showed that CP treatment was more sensitive to drought stress, and drought stress had more influence on the shoots of CP treatment than the roots. While the effect of drought stress on LP treatment roots were greater than that on shoots. With the extension of drought stress, the effect on sugar metabolism was greater.

\section{Conclusions}

The wheat plants under LP treatment was more adaptive to drought stress than that in CP treatment, which probably is based on the presence of the comprehensive mobilization of sugar metabolism responsible for the regulation of osmotic balance, as well as the accumulation of various organic acids responsible for the maintenance of the intracellular ion homeostasis.

\section{Background}

Worldwide, wheat (Triticum aestivum L.) is the main food crop, and about $70 \%$ of the world's wheat planting areas are distributed in arid or semi-arid agricultural areas [1]. Environmental constraint factors, including low soil nitrogen, insufficient phosphorus levels, and drought conditions are important for wheat production in most of the areas where wheat is grown [2-6].

Phosphorus is one of the essential nutrient elements in the growth and development of wheat. Previous studies reported that the general strategies, such as mycorrhizal symbiosis, reduced growth rate, reactivation of inorganic phosphorus in the plants, change carbon metabolism by passing phosphorus-requiring steps, increase the production and secretion of phosphatase, secrete organic acids, change root architecture, and enhance the expression of $\mathrm{Pi}$ transporter, were evolved by plants for phosphorus acquisition and use under the constraint growth environments [710]. Moreover, there is a significant interaction between phosphorus nutrition and water stress. Under the condition of soil drought, proper application of phosphorus fertilizer can significantly improve the water status of plants, improve the stability of plant cell membrane, and maintain the normal growth and physiological process of plants. Appropriate application of phosphate fertilizer can, to some extent, make up for the adverse effects caused by insufficient water, and significantly improve the yield and water utilization rate of wheat [11-13]. 
Metabolite profiling is rapidly becoming a key tool for functional annotation of genes, and it facilitates comprehensive understanding of cellular responses to variations in biological conditions [14]. In wheat, the metabolite profiling in response to salt stress [15], temperature [16], $\mathrm{N}$ nutrition [17] and drought stress has been analyzed [18]. Plant responses to drought stress may involve metabolic pathways, such as photosynthesis, sugar synthesis, tricarboxylic acid cycle, glycolysis and hormone synthesis [19-21]. Metabolomic solutes, such as proline, betaine, fructose and sucrose, contribute to drought stress tolerance [22-24]. Metabolomic components may also participate in plant drought tolerance; however, information regarding combined phosphorus and drought stress related metabolomic components is limited. Drought stress has many influences on plant metabolism, such as growth inhibition, water content decrease, photosynthesis and respiration rate decrease, and changes in various enzyme activities, biological macromolecule damage, protein degradation, and large amount of cell content extravasation [25]. All these processes are closely related to metal ions [26]. Ion balance in plants plays an important role in maintaining the normal growth and development of crops, and ion imbalance will hinder the normal growth of plants. Therefore, studying the absorption, transport and distribution of metal ions under drought conditions is of great significance for studying the mechanism of plant drought damage and the role of metal ions in drought damage and improving the stress resistance of crops.

It was found that $\mathrm{Na}^{+}$in soil salt would be toxic to plants and have an antagonistic effect with the absorption of other ions $\left(\mathrm{K}^{+}, \mathrm{Ca}^{2+}\right)$, leading to nutrient deficiency and affecting the normal growth of plants [27]. Previous studies on the relationship between the development of primary root hairs and $\mathrm{K}^{+}$flux in drought-resistant and drought-sensitive wheat before and after drought treatment showed that the development of primary root hairs of wheat were infected by net $\mathrm{K}^{+}$flux. The number of primary root hairs of drought-resistant wheat was more than that of drought-sensitive wheat for strong ability of $\mathrm{K}^{+}$absorption [28]. Wheat seedlings grown under normal water condition had a small amount of $\mathrm{Ca}^{2+}$ in their chloroplasts. With the extension of water stress time, the free $\mathrm{Ca}^{2+}$ in chloroplast increased gradually, and the damage to the ultrastructure of chloroplast was more serious. After rehydration, the level of free $\mathrm{Ca}^{2+}$ in chloroplast decreased gradually, and the chloroplast structure returned to normal gradually [18, 29]. However, few studies of ion changes was reported in wheat under combined phosphorus and drought stress in winter wheat.

Under drought stress, the synergistic effect of phosphorus is obvious, which helps to enhance the drought resistance of root system, promote the growth of crop root system and increase crop yield [30-31]. However, the physiological and metabolomics analysis and ion status of wheat plants under water and phosphorus coupling stress has not been reported. In this study, we selected the elite wheat genotype "Xindong20" to investigate the changes of physiological characteristics, metabolomics profiling and ion status under drought stress and rehydration conditions between two phosphorus levels. These results will provide a basis for our better understanding of the adaptation mechanisms to drought stress under different phosphorus condition.

\section{Methods}

\section{Plant materials, phosphorus and drought treatment}

The winter wheat "Xindong 20" was used as experimental material, which were kindly provided by the Agriculture College of Shihezi University. Full and uniform wheat seeds were selected and sterilized in $1 \%$ o $\mathrm{HgCl}_{2}$ solution for 30 s, washed with distilled water for several times, and placed evenly in a petri dish covered with wet filter paper. The petri dishes with seeds were placed in an incubator in the dark at $20^{\circ} \mathrm{C}$ to promote germination. During the period, distilled water was poured at an interval of $2 d$ to keep them moist. When the seedlings grow to one leaf (about $7 d$, counted from sowing), select the seedlings with good growth and consistent to transfer to the black plastic culture box to keep 
roots dark. Each box contained the same capacity of Hoagland nutrient solution, which were used with conventional phosphorus level of $1.0 \mathrm{mmol} / \mathrm{L}(\mathrm{CP})$ and low phosphorus level of $0.05 \mathrm{mmol} / \mathrm{L}(\mathrm{LP})$. $\mathrm{KCl}$ was used to replace part of $\mathrm{KH}_{2} \mathrm{PO}_{4}$ in low phosphorus condition. The normal light culture was carried out with an $18 \mathrm{~h}$ day-length at $25^{\circ} \mathrm{C}$ under photosynthetically active light $\left(250 \mu \mathrm{mole} / \mathrm{m}^{2} / \mathrm{s}\right)$ and a night temperature of $20^{\circ} \mathrm{C}$. After $14 \mathrm{~d}$ of culture, Hoagland nutrient solution of CP and LP was prepared with 15\% (w/v) PEG-6000 to simulate drought stress, respectively. After $7 d$ of drought stress, Hoagland nutrient solution without PEG-6000 was used to rehydrate for $3 d$. Samples were taken at $0 d, 3 d, 5 d, 7 d$ under drought stress and $3 d$ of rehydration, respectively.

\section{Biomass measurement}

The shoots and roots of different treatments were harvested, respectively. Part of them dried at $70^{\circ} \mathrm{C}$ to constant weight and weighed. The remaining samples were weighted the fresh weight. At least five biological replicates were used for biomass measurements.

\section{Root morphology}

The root samples were washed with distilled water, and the surface water was drained with a filter paper. The roots were completely spread to avoid overlap. The prepared root were scanned by using the root scanning system (Wanshen LS-A, Phantom 9850XL PLUS, China) according to the manufacturer's instructions. WinRHIZO PRO2009 software was used to analyze the average root diameter and total root volume.

\section{DNA extraction and fragmentation analysis}

The DNA was extracted from frozen root by using EasyPure Plant Genomic DNA kits (Transgen, Code\#9192EE111-01, China) according to the manufacturer's instructions. The quality and concentration of genomic DNA were measured using a nucleic acid protein analyzer (NanoDrop, ND-1000, USA). The same sample amount was maintained for each treatment at each period. Ethidium bromide staining and $1.5 \%$ agarose gel electrophoresis were used to visualize the DNA fragments.

\section{Sample preparation and untargeted metabolomic analysis}

The metabolite analysis were finished with the assist of BGI Biotechnology Corporation. Metabolite analysis by GCMS was carried out. Briefly, five biological replicates of each sample were set. $25 \mathrm{mg}$ samples stored at $-80^{\circ} \mathrm{C}$ were placed in an EP tube, respectively, and then $800 \mu \mathrm{l}$ of chilled methanol/water (1:1) buffer solution and two small steel balls were added to each EP tube. The samples were grind by Tissuelyser, with the parameter set at $55 \mathrm{~Hz}$ and $4 \mathrm{~min}$. After grinding, the steel ball was taken out, and the centrifuge tube was placed at $-20^{\circ} \mathrm{C}$ for precipitation. And then the samples was centrifuged at $30,000 \mathrm{~g}$ for $20 \mathrm{~min}$ at $4^{\circ} \mathrm{C}$. $550 \mu \mathrm{l}$ of supernatant (containing extracted metabolites) was transferred to a fresh tube. $20 \mu$ l of each sample were taken and mix them into QC samples. The samples were then subjected to GC-MS analysis.

Prepared samples were injected onto the GC column in splitless mode using the GC-MS instrument 2777C UPLC system (Waters U.K.). The samples were randomized to reduce system error. The data were acquired in one batch and finished in 1 day. The GC column was ACQUITY UPLC CSH C18 $(100 \mathrm{~mm} \times 2.1 \mathrm{~mm}, 1.7 \mu \mathrm{m}$, Waters U.K.) .

The main parameters are as follows: $0.1 \%$ acetonitrile / water (60:40) for mobile phase A, isopropyl alcohol/ acetonitrile (90:10) for mobile phase $B$. The injection volume is $10 \mu \mathrm{l}$. The flow rate was $0.4 \mathrm{ml} / \mathrm{min}$. The column temperature is $40^{\circ} \mathrm{C}$. The gradient elution program was as follows: $0-2 \mathrm{~min}, 60 \% \mathrm{~A}, 40 \% \mathrm{~B}$ phase; $2-2.1 \mathrm{~min}, 57 \% \mathrm{~A}$, 43\% B phase; 2.1-6 min, 50\% A, 50\% B phase; 6-6.1 min, 46\% A, 54\% B phase;6.1-8 min, 30\% A, 70\% B phase; 8-8.1 min, 1\% A, 99\% B-phase; 8.1-10 min, 60\% A, 40\% B phase. Electrospray ionization (ESI+/ESI-) mode was used for mass 
spectrometry, and the scanning mode was positive and negative ion mode, respectively. The capillary voltage is $0.25 \mathrm{Kv}(+) / 2 \mathrm{Kv}(-)$.

\section{Element content analysis}

The seedlings with uniform growth under CP and LP treatment were randomly collected, respectively (set 5 biological replicates). The shoot and roots were separated for element content analysis by using Agilent ICP-OES 710 (Agilent, USA). The element standard solution $(1000 \mu \mathrm{g} / \mathrm{ml})$ was measured and diluted with $2 \%$ nitric acid to prepare the standard curve. Briefly, the oven-dried sample of $0.1 \mathrm{~g}$ was put in a polytetrafluoroethylene beaker, and then $10 \mathrm{ml}$ of nitric acid was added. The mixture was heated on the hot plate for $12 \mathrm{~h}$, and then digested at $150^{\circ} \mathrm{C}$ until the rest liquid was $2 \sim 3 \mathrm{ml}$. After transferring the cooled rest liquid above to $20 \mathrm{ml}$ volumetric flask, dilute with $2 \%$ nitric acid to constant volume. Meanwhile, the blank test was done.

\section{Statistical analysis and image processing}

Statistical analysis of all data were performed using Microsoft Excel and SPSS 13.0 software. T-tests were used for pairwise comparisons.

In the statistical analysis, the p-value produced by rank sum test was further corrected by FDR to obtain the q-value. The essential factors for crop screening of differential metabolites were usually the difference multiple greater than 1.2 or less than 0.8 and q-value less than 0.05 . Peak extraction was mainly realized by commercial software Progenesis QI (Version 2.0), including peak alignment, peak extraction, normalization, deconvolution and compound identification. Additionally, to avoid false-positive results in the screening for significant metabolites, the false discovery rate (FDR) significance criterion was used and an FDR limit of 0.05 selected. To perform a general and comprehensive characterization between the treatments groups, the detected compounds were subjected to a principal components analysis (PCA), the acquiescent set was Pareto-scaled, and the key metabolites of the samples were identified by partial least-squares discriminant analysis (PLS-DA).

\section{Results}

\section{Morphological and physiological characteristics of wheat root}

As shown in Fig. 1, drought stress had a significant effect on the root growth of wheat plants. At Od under drought stress, the upper roots under LP treatment were thicker than that under CP treatment. Consistent with drought stress for $0 \mathrm{~d}$, LP treated roots were thicker than CP under drought stress for 7d (D7), but the roots began to turn yellow. The obvious root tip enlargement was observed at root tips of each root and bifurcate root, which was more obvious in CP treatment (Fig. 1).

Consistent with root morphology, at $0 \mathrm{~d}, 5 \mathrm{~d}$ and $7 \mathrm{~d}$ under drought stress, the total root volume of LP treatment was significantly higher than that of CP (Fig. 2). The average diameter of roots cultured by two phosphorus levels showed no significant difference under drought stress for $0 d, 7 d$ and rehydration for $3 d$ (R3), respectively.

As shown in Figure. 3, from 0d to 3d under drought stress, plant dry weight and fresh weight of LP and CP treatments showed a gradual upward trend, but LP was lower than CP treatment (including root, shoot and the whole plant). However, from D5 to R3, the increase trend of plant dry weight and fresh weight under LP treatment was significantly higher than that under CP treatment. The fresh weight and dry weight of roots in CP even showed a downward trend. Especially at R3, LP was significantly or extremely significantly higher than CP treatment. 


\section{DNA laddering detection}

To investigate the effect of drought stress on programmed cell death in root tissue under two phosphorus levels, DNA from root tip was extracted and gel electrophoresis was performed. The results showed that the characteristics of DNA ladder from 0d to 7d under drought stress were gradually obvious, and the band intensity at D7 was the brightest (Fig. 4). Meanwhile, the laddering intensity of LP treatment was stronger than that of CP. After 3d of rehydration, the ladder brightness of the two treatments became significantly weaker, while LP treatment was significantly weaker than $\mathrm{CP}$, indicating that the recovery ability of root tissues under LP treatment was stronger than CP.

\section{Metabolic profiling of the response of wheat plant to phosphorus and drought}

In order to understand in more detail the difference of wheat response to drought stress under two phosphorus levels, metabolites in shoots and roots were detected by LC-MS/MS, respectively. The characteristic ions of RSD $<30 \%$ in QC samples were used for further analysis. The results showed that under positive ion mode, there were 102 differentially expressed ions in the root system at D3, among which 64 differentially expressed ions were up-regulated and 38 differentially expressed ions were down-regulated, involving 10 differentially expressed pathways (Table 1). In addition, no significantly different positive ions were detected in the shoots at D3 and D7 and in the roots at D7, respectively. In negative ion mode, at D3, there were 11 differentially expressed ions in the shoots, among which 9 were up-regulated and 2 were down-regulated, involving 2 differentially expressed pathways. At D7, there were 46 differentially expressed ions in the roots, among which 8 were up-regulated and 38 were down-regulated, involving 19 differentially expressed pathways. In addition, no significantly different negative ions were detected in the roots at D3 and the shoots at D7 (Table 1). The number of difference ions in the root was higher than that in the shoots, indicating that the root was more sensitive to the stress environment. The difference between tissues is greater than those between stress periods.

Table 1

The comparison of ion and metabolites pathway with significant differences between LP and CP in Xindong20.

\begin{tabular}{|c|c|c|c|c|c|c|c|c|c|}
\hline \multirow[t]{2}{*}{ Tissue } & \multirow{2}{*}{$\begin{array}{l}\text { Days for } \\
\text { drought } \\
\text { treatment }\end{array}$} & \multicolumn{4}{|c|}{ Positive ion mode } & \multicolumn{4}{|c|}{ Negative ion mode } \\
\hline & & $\begin{array}{l}\text { Differential } \\
\text { ion number }\end{array}$ & Up & Down & $\begin{array}{l}\text { Differential } \\
\text { pathway }\end{array}$ & $\begin{array}{l}\text { Differential } \\
\text { ion number }\end{array}$ & Up & Down & $\begin{array}{l}\text { Differentia } \\
\text { pathway }\end{array}$ \\
\hline shoot & $3 d$ & 0 & 0 & 0 & 0 & 11 & 9 & 2 & 2 \\
\hline shoot & $7 d$ & 0 & 0 & 0 & 0 & 0 & 0 & 0 & 0 \\
\hline root & $3 d$ & 102 & 64 & 38 & 10 & 0 & 0 & 0 & 0 \\
\hline root & $7 d$ & 0 & 0 & 0 & 0 & 46 & 8 & 38 & 19 \\
\hline
\end{tabular}

In this study, metabolites in root and shoot of wheat cultured by two phosphorus levels and sampled at D3 and D7 were studied by metabolomics method. It was found that there were significant differences in metabolites in root and shoots of wheat induced by drought stress under LP and CP treatment. Among them, in CP treatment, 67 differential metabolic pathways involving 598 differential metabolites were detected in the shoots at D3 compared to D7 (Supplementary table 1), while no differential metabolites were detected under LP treatment. The differential metabolites under CP treatment involved 8 metabolic pathways, most of which were up-regulated (Supplementary Table 2).There were 120 differential metabolites under LP treatment, involving 39 metabolic pathways, most of which were up-regulated (Supplementary Table 3). It indicated that under the supply of two levels of phosphorus, drought 
stress had a greater influence on CP treatment than LP, among which the influence on CP treatment shoots was greater than that on root. While the effect of drought stress on LP treatment root was greater than that on shoot.

At 3d under drought stress, compared with the CP treatment, only 2 differential metabolic pathways were detected in shoot tissue under LP condition. The first pathway was named flavonoid biosynthesis, and the differential metabolite involved was xanthohumol, with a significant increase of 5.019 fold. The other differential metabolic pathway is phenylpropanoid biosynthesis, and the differential metabolite involved is 1-0-Sinapoyl- $\beta$-D-glucose, with a significant increase of 4.469 fold (Table 2).

Table 2

Metabolite comparison with significant differences in the shoots of Xindong 20 at D3 between LP and CP treatments.

\begin{tabular}{|lll|}
\hline Metabolic pathways & Metabolites name & Fold changes (LP/CP) \\
\hline Flavonoid biosynthesis & Xanthohumol & 5.019 \\
\hline Phenylpropanoid biosynthesis & 1-O-Sinapoyl-ß-D-glucose & 4.469 \\
\hline
\end{tabular}

GC-MS-based metabolomic analysis between LP and CP groups resulted in identification of 10 differential metabolic pathways involved 28 differential metabolites in the roots at D3. Among them, strictosidine aglycone, horhammericine, dialdehyde, strictosidine aglycone and 11-deoxycorticosterone was the highest, reaching 1.85 fold, respectively. Most of them have multiples of less than 1 (Table 3). 
Table 3

Metabolite comparison with significant differences in the roots of Xindong 20 at D3 between LP and CP treatments, respectively*.

\begin{tabular}{|c|c|c|c|c|c|}
\hline $\begin{array}{l}\text { Metabolic } \\
\text { pathways }\end{array}$ & Metabolites name & $\begin{array}{l}\text { Fold } \\
\text { changes } \\
(\mathrm{LP} / \mathrm{CP})\end{array}$ & $\begin{array}{l}\text { Metabolic } \\
\text { pathways }\end{array}$ & Metabolites name & $\begin{array}{l}\text { Fold } \\
\text { changes } \\
(L P / C P)\end{array}$ \\
\hline \multirow[t]{3}{*}{$\begin{array}{l}\text { Indole alkaloid } \\
\text { biosynthesis }\end{array}$} & $\begin{array}{l}\text { Strictosidine } \\
\text { aglycone }\end{array}$ & \multirow{3}{*}{$\begin{array}{l}1.85 \\
1.85 \\
1.85\end{array}$} & \multirow{3}{*}{$\begin{array}{l}\text { Sesquiterpenoid } \\
\text { and triterpenoid } \\
\text { biosynthesis }\end{array}$} & Solavetivone & 0.42 \\
\hline & Horhammericine & & & Pentalen-13-al & 0.4 \\
\hline & Dialdehyde & & & Albaflavenone & 0.42 \\
\hline $\begin{array}{l}\text { Phenylpropanoid } \\
\text { biosynthesis }\end{array}$ & $\begin{array}{l}\text { 1-O-Sinapoyl- } \beta-D- \\
\text { glucose }\end{array}$ & 0.58 & \multirow[t]{5}{*}{$\begin{array}{l}\text { Metabolic } \\
\text { pathways }\end{array}$} & $\begin{array}{l}\text { 5'- } \\
\text { Methylthioadenosine }\end{array}$ & 0.23 \\
\hline $\begin{array}{l}\text { Plant hormone } \\
\text { signal } \\
\text { transduction }\end{array}$ & Abscisate & 0.51 & & $\begin{array}{l}\text { Strictosidine } \\
\text { aglycone }\end{array}$ & 1.85 \\
\hline $\begin{array}{l}\text { Carotenoid } \\
\text { biosynthesis }\end{array}$ & Abscisic acid & 0.51 & & $\begin{array}{l}\text { 11- } \\
\text { Deoxycorticosterone }\end{array}$ & 1.85 \\
\hline $\begin{array}{l}\text { Cysteine and } \\
\text { methionine } \\
\text { metabolism }\end{array}$ & $\begin{array}{l}5^{\prime}- \\
\text { Methylthioadenosine }\end{array}$ & 0.23 & & Abscisate & 0.51 \\
\hline \multirow[t]{4}{*}{$\begin{array}{l}\text { Zeatin } \\
\text { biosynthesis }\end{array}$} & $\begin{array}{l}\text { O-ß-D- } \\
\text { Glucopyranosyl-cis- } \\
\text { zeatin }\end{array}$ & 0.58 & & $\begin{array}{l}17 a- \\
\text { Hydroxypregnenolone }\end{array}$ & 0.52 \\
\hline & $\begin{array}{l}\text { trans-Zeatin-7- } \beta \text {-D- } \\
\text { glucoside }\end{array}$ & 0.58 & $\begin{array}{l}\text { Isoquinoline } \\
\text { alkaloid } \\
\text { biosynthesis }\end{array}$ & Magnoflorine & 0.59 \\
\hline & O-ß-D-Glucosylzeatin & 0.58 & & & \\
\hline & $\begin{array}{l}5^{\prime}- \\
\text { Methylthioadenosine }\end{array}$ & 0.23 & & & \\
\hline
\end{tabular}

Through KEGG enrichment analysis, we found that,in the wheat roots of the group between LP and CP】there were 81 differentially expressed metabolites at D7, involving 19 metabolic pathways. According to the number of differential metabolites, the sequence from high to low is: metabolic pathways $\square$ fructose and mannose metabolism $\square$ biosynthesis of secondary metabolites $\square$ amino sugar and nucleotide sugar metabolism $\square$ galactose metabolism $\square$ carbon

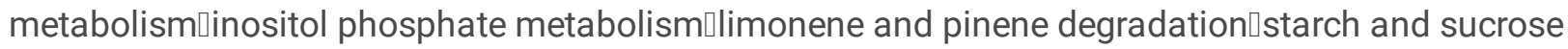

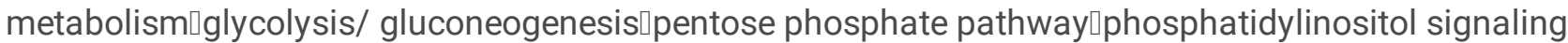
system $\square$ ascorbate and aldarate metabolism $\square$ biosynthesis of amino acids $\llbracket$ carbon fixation in photosynthetic organisms $\square$ phenylalanine, tyrosine and tryptophan biosynthesis $\square$ pentose and glucuronate interconversions $\square A B C$ transporters $\square$ cutin, suberine and wax biosynthesis (Table 4). All of them have multiples of less than 1. 
Table 4

Metabolite comparison with significant differences in the roots of Xindong 20 at D7 between LP and CP treatments, respectively*.

\begin{tabular}{|c|c|c|c|c|c|}
\hline Metabolic pathways & Metabolites name & $\begin{array}{l}\text { Fold } \\
\text { changes } \\
(\mathrm{LP} / \mathrm{CP})\end{array}$ & $\begin{array}{l}\text { Metabolic } \\
\text { pathways }\end{array}$ & $\begin{array}{l}\text { Metabolites } \\
\text { name }\end{array}$ & $\begin{array}{l}\text { Fold } \\
\text { changes } \\
(\mathrm{LP} / \mathrm{CP})\end{array}$ \\
\hline \multirow[t]{3}{*}{$\begin{array}{l}\text { Phosphatidylinositol } \\
\text { signaling system }\end{array}$} & Inositol 1-P & 0.058 & \multirow[t]{5}{*}{$\begin{array}{l}\text { Carbon } \\
\text { metabolism }\end{array}$} & $\begin{array}{l}\text { D-arabino- } \\
\text { Hex-3-ulose } \\
6-P\end{array}$ & 0.058 \\
\hline & myo-Inositol 4-P & & & $\begin{array}{l}\beta-D- \\
\text { Fructose 6- } \\
P\end{array}$ & \\
\hline & 1D-myo-Inositol 3-P & & & $\begin{array}{l}\text { a-D- } \\
\text { Glucose 6- } \\
P\end{array}$ & \\
\hline \multirow[t]{4}{*}{$\begin{array}{l}\text { Inositol phosphate } \\
\text { metabolism }\end{array}$} & D-Glucose 6-P & 0.058 & & $\begin{array}{l}\text { D-Fructose } \\
6-P\end{array}$ & \\
\hline & Inositol 1-P & & & $\begin{array}{l}\beta-D- \\
\text { Glucose 6- } \\
P\end{array}$ & \\
\hline & myo-Inositol 4-P & & $\begin{array}{l}\text { Pentose and } \\
\text { glucuronate } \\
\text { interconversions }\end{array}$ & $\begin{array}{l}\text { D-Glucose } \\
1-P\end{array}$ & 0.058 \\
\hline & 1D-myo-Inositol 3-P & & \multirow{4}{*}{$\begin{array}{l}\text { Starch and } \\
\text { sucrose } \\
\text { metabolism }\end{array}$} & $\begin{array}{l}\text { D-Glucose } \\
6-P\end{array}$ & 0.058 \\
\hline \multirow[t]{2}{*}{$\begin{array}{l}\text { Ascorbate and aldarate } \\
\text { metabolism }\end{array}$} & L-Gulose 1-P & 0.058 & & $\begin{array}{l}\text { D-Glucose } \\
1-P\end{array}$ & \\
\hline & $\beta$-L-Galactose 1-P & & & $\begin{array}{l}\text { D-Fructose } \\
6-P\end{array}$ & \\
\hline \multirow[t]{6}{*}{$\begin{array}{l}\text { Amino sugar and } \\
\text { nucleotide sugar } \\
\text { metabolism }\end{array}$} & a-D-Galactose 1-P & 0.058 & & $\begin{array}{l}\beta \text {-D- } \\
\text { Glucose 1- } \\
\text { P }\end{array}$ & \\
\hline & D-Mannose 6-P & & $\mathrm{ABC}$ transporters & Inositol 1-P & 0.058 \\
\hline & $\beta$-D-Fructose 6-P & & $\begin{array}{l}\text { Glycolysis / } \\
\text { Gluconeogenesis }\end{array}$ & $\begin{array}{l}\beta-D- \\
\text { Fructose 6- } \\
P\end{array}$ & 0.058 \\
\hline & a-D-Glucose 6-P & & & $\begin{array}{l}\text { a-D- } \\
\text { Glucose 6- } \\
\text { P }\end{array}$ & \\
\hline & D-Glucose 1-P & & & $\begin{array}{l}\text { D-Glucose } \\
1-P\end{array}$ & \\
\hline & D-Mannose 1-P & & & $\begin{array}{l}\beta-D- \\
\text { Glucose 6- } \\
P\end{array}$ & \\
\hline
\end{tabular}

*Note: the pathways of Biosynthesis of secondary metabolites involved 8 differential metabolite and the metabolic pathway involved 17 differential metabolite were not shown. 


\begin{tabular}{|c|c|c|c|c|c|}
\hline Metabolic pathways & Metabolites name & $\begin{array}{l}\text { Fold } \\
\text { changes } \\
(\mathrm{LP} / \mathrm{CP})\end{array}$ & $\begin{array}{l}\text { Metabolic } \\
\text { pathways }\end{array}$ & $\begin{array}{l}\text { Metabolites } \\
\text { name }\end{array}$ & $\begin{array}{l}\text { Fold } \\
\text { changes } \\
\text { (LP/CP) }\end{array}$ \\
\hline $\begin{array}{l}\text { Carbon fixation in } \\
\text { photosynthetic } \\
\text { organisms }\end{array}$ & D-Fructose 6-P & 0.058 & \multirow[t]{2}{*}{$\begin{array}{l}\text { Biosynthesis of } \\
\text { amino acids }\end{array}$} & $\begin{array}{l}\text { D-arabino- } \\
\text { Hex-3-ulose } \\
6-P\end{array}$ & \multirow[t]{2}{*}{0.058} \\
\hline $\begin{array}{l}\text { Phenylalanine, tyrosine } \\
\text { and tryptophan } \\
\text { biosynthesis }\end{array}$ & D-Fructose 1-P & 0.058 & & $\begin{array}{l}\beta \text {-D- } \\
\text { Fructose 6- } \\
P\end{array}$ & \\
\hline \multirow[t]{4}{*}{$\begin{array}{l}\text { Limonene and pinene } \\
\text { degradation }\end{array}$} & $\begin{array}{l}\text { (3S)-6-Hydroxy-3- } \\
\text { isopropenyl- } \\
\text { heptanoate }\end{array}$ & \multirow[t]{4}{*}{0.12} & $\begin{array}{l}\text { Cutin, suberine } \\
\text { and wax } \\
\text { biosynthesis }\end{array}$ & $\begin{array}{l}\text { 16-Oxo- } \\
\text { palmitate }\end{array}$ & 0.17 \\
\hline & $\begin{array}{l}\text { (5R)-6-Hydroxy-5- } \\
\text { isopropenyl-2- } \\
\text { methylhexanoate }\end{array}$ & & \multirow[t]{7}{*}{$\begin{array}{l}\text { Fructose and } \\
\text { mannose } \\
\text { metabolism }\end{array}$} & $\begin{array}{l}\text { D-Mannose } \\
\text { 6-P }\end{array}$ & \multirow[t]{7}{*}{0.058} \\
\hline & $\begin{array}{l}\text { (3R)-6-Hydroxy-3- } \\
\text { isopropenyl- } \\
\text { heptanoate }\end{array}$ & & & $\begin{array}{l}\beta-D- \\
\text { Fructose 6- } \\
P\end{array}$ & \\
\hline & $\begin{array}{l}\text { (5S)-6-Hydroxy-5- } \\
\text { isopropenyl-2- } \\
\text { methylhexanoate }\end{array}$ & & & $\begin{array}{l}\text { D-Allose 6- } \\
\text { P }\end{array}$ & \\
\hline \multirow[t]{8}{*}{ Galactose metabolism } & a-D-Galactose 1-P & \multirow[t]{8}{*}{0.058} & & $\begin{array}{l}\beta \text {-D- } \\
\text { Fructose 2- } \\
P\end{array}$ & \\
\hline & D-Tagatose 6-P & & & $\begin{array}{l}\text { D-Fructose } \\
1-P\end{array}$ & \\
\hline & a-D-Glucose 6-P & & & $\begin{array}{l}\text { Sorbose 1- } \\
\text { P }\end{array}$ & \\
\hline & D-Glucose 1-P & & & $\begin{array}{l}\text { D-Mannose } \\
\text { 1-P }\end{array}$ & \\
\hline & D-Galactose 6-P & & \multirow[t]{4}{*}{$\begin{array}{l}\text { Pentose } \\
\text { phosphate } \\
\text { pathway }\end{array}$} & $\begin{array}{l}\text { D-arabino- } \\
\text { Hex-3-ulose } \\
6-P\end{array}$ & \multirow[t]{4}{*}{0.058} \\
\hline & & & & $\begin{array}{l}\beta \text {-D- } \\
\text { Fructose 6- } \\
P\end{array}$ & \\
\hline & & & & $\begin{array}{l}\text { a-D- } \\
\text { Glucose 6- } \\
P\end{array}$ & \\
\hline & & & & $\begin{array}{l}\text { B-D- } \\
\text { Glucose 6- } \\
P\end{array}$ & \\
\hline
\end{tabular}

\section{The changes of elements in the roots and shoots}


In order to explore the response of wheat to drought stress at two phosphorus levels, the changes of 11 elements in roots and shoots were measured by mass spectrometry at D7 and R3 (Fig. 5). The results showed that 8 elements in the roots measured under LP treatment significantly decreased compared with CP at D7, including K, $\mathrm{Ca}, \mathrm{P}, \mathrm{Si}, \mathrm{Na}, \mathrm{Mn}$, $\mathrm{Mg}$ and $\mathrm{Zn}$, respectively. The $\mathrm{P}$ content decreased by $85.8 \%$, followed by $69.3 \%$ in $\mathrm{Mn}$, by $62.5 \%$ in $\mathrm{Zn}$ and $62.1 \%$ in $\mathrm{Mg}$. Fe and S contents increased significantly, by $79.6 \%$ and $37.9 \%$ respectively. The change of Cu content was not significant. After rehydration for 3d, under LP treatment, the contents of 8 elements were significantly lower than that of the CP, namely, K, Ca, P, Si, Mg, Cu, Zn and S, in which P decreased by $68.6 \%$, Zn by $51 \%$ and Cu by $47.5 \%$, respectively. Mn and Fe contents were significantly higher than $\mathrm{CP}$, increasing by $53.8 \%$ and $208.2 \%$, respectively. There was no significant difference in Na content. Under LP treatment, the contents of K, P, Si, Mn, Mg, Zn, Ca and Fe at R3 increased significantly, increasing by $42.5 \%, 155.3 \%, 102.9 \%, 120.4 \%, 75.3 \%, 81.1 \%, 21.0 \%$ and $60.14 \%$, respectively, compared with D7. Na and S contents decreased significantly, by $38 \%$ and $46.1 \%$, respectively, and Cu content did not change significantly. Under CP treatment, the contents of P, Si, Cu and Zn increased significantly at R3 compared with D7, up to $15.6 \%, 109.1 \%, 82.1 \%$ and $38.3 \%$, respectively. The contents of $\mathrm{K}, \mathrm{Na}, \mathrm{Mn}, \mathrm{Ca}$ and $\mathrm{Mg}$ decreased significantly, which were $24.1 \%, 67.4 \%, 56.1 \%, 19.27 \%$ and $10.5 \%$, respectively. Fe and S contents did not change significantly.

\section{Discussion}

\section{Morphological and physiological changes in response to drought stress under two phosphorus levels}

The phenotype of the wheat plant is an outward manifestation of all biological processes. In this study, short term drought (3d) had little effect on dry and fresh weight of wheat plants under the two conditions of phosphorus application. However, starting from $3 d$ of drought stress, the influence of drought stress on normal phosphorus application is greater than that of low phosphorus treatment. From 5D to R3, CP treatment presents basically the same or gradually decreasing trend of dry and fresh weight of plants, while LP treatment presents a gradually increasing trend of dry and fresh weight of plants. Morphological changes of the root system were consistent with the above results. The root system at $0 \mathrm{~d}$ and $7 \mathrm{~d}$ under drought stress in LP was dense, and the total volume was significantly higher than that under CP. The experiment of soil cultivation also confirmed the promoting effect of stress environment on the growth and development of wheat root hairs [32]. Studies in common beans also showed that the ratio of the root to shoot increased in phosphorus-insufficient plants as compared to phosphorus-sufficient plants. It was speculated that the proliferation of lateral roots may partially contribute the variation of the ratio under phosphorus stress [33]. Moreover, the studies in Arabidopsis also showed that phosphate starvation can induce determinant root development [34]. Quantitative trait loci of root architecture traits associated with phosphorus acquisition in soybean have been identified, which further indicates the importance of root structure for low phosphorus adaptation in soybean [35]. The change of root architecture under phosphorus deficiency is the result of the internal balance of auxin, cytokinin and ethylene [36-41]. As one would expect, in this study, we found several differential metabolic pathways and metabolites involving plant hormone synthesis and phosphorus reactivity, such as: plant hormone signal transduction, indole alkaloid biosynthesis, phosphatidylinositol signaling system, and abscisic acid, in wheat root. With the increase of lateral root growth, the response of genes related to cell wall synthesis and growth to phosphorus was accelerated. For instance, the expression of the gene coding cell wall invertase was significantly increased [42].

Phosphorus participates in glycolysis process, which can enhance respiration action, make saccharide forms a variety of organic acids as ammonia receptor and form amino acid. Phosphorus is indispensable in the process of protein synthesis and enzyme activity regulation [33]. In addition, it is irreplaceable in the phosphorylation and dephosphorylation of proteins and the energy transfer of ATP in the process of information transmission. When 
phosphorus is deficient, protein synthesis is blocked, which affects the cell cycle [43]. Studies have shown that zeatin can affect cell cycle by regulating CYCD3 gene [44]. At the same time, phosphorus stress can also affect the cell cycle and induce the changes of endoploidy in plants [45]. As expected, zeatin biosynthesis related differential metabolites treated with LP were significantly reduced in this study, suggesting changes in the polyploidy level in root cells induced by LP. In addition, limited nutrition is an important factor in limiting cell division. Sucrose is a major transport carbon source in plants and plays an important regulatory role in cell cycle progression [46]. In this study, under LP treatment, sucrose metabolic pathways were inhibited, thus affecting sugar production and inhibiting cell division process, which may induce endoploidy changes in root cells. In present study, the phenomenon of root tip enlargement at D7 was more obvious in CP compared to LP. This phenomenon may be related to endoploidy of root cells, and the level of endoploidy of LP may be lower than that of CP treatment. Previous studies showed that under the stress of low phosphorus, the polyploidy level in both the mature area of the main root and the lateral root of barley plants decreased significantly, and the extent of the polyploidy level in the lateral root decreased more than that in the main root [45], which may consistent with the results of this study. Previous studies reported that the decrease of endoploidy occurred in both root and leaf under different stress conditions [47]. The reduction of endopolyploidy is helpful to reduce the input of carbon source and other nutrient elements in the process of effective utilization of water and mineral nutrients, while increasing the photosynthetic area. This is especially important for plants under abiotic stress, such as phosphorus stress, because photosynthesis is greatly affected, but more photosynthetic products are transported to the roots [48]. In addition, based on the important role of phosphorus in C, N and other metabolic pathways, plant cells often need to maintain phosphorus concentration within a certain range even under the condition of phosphorus deficiency [49]. Therefore, in the case of limited phosphorus content, saving the consumption of phosphorus is very important for plant survival. Studies have shown that $59-64 \%$ of the total phosphorus content in the roots of plants growing under low phosphorus conditions comes from nucleic acid substances [50]. High endopolyploidy levels increase the amount of rRNA, one of the main components of nucleic acids. Therefore, under the condition of low phosphorus, the reduction of polyploidy level in lateral roots contributes to the reduction of phosphorus consumption in the synthesis process of genomic DNA, RNA and other phosphorylated metabolites, and ultimately contributes to the better environmental adaptation of plants. In addition, DNA ladder detection of root tips also showed that,although the roots cultured by two phosphorus levels underwent the process of program of cell death under drought stress, the genomic DNA degradation level of the roots in LP was significantly weaker than that in CP. It indicates that the recovery ability of wheat plant under LP is higher than that in CP treatment after rehydration. This is consistent with root morphology and weight accumulation.

\section{Ionomic changes in responses to drought stress under two phosphorus levels}

Under drought stress, water metabolism in plants was seriously affected, and metal ion metabolism closely related to water metabolism was also affected. In this study, under the drought stress and rehydration condition, different phosphorus supply has a great influence on mineral elements contents. At D7 and R3, the concentrations of most elements measured in the roots significantly decreased under LP treamemt, however, the contents of Fe and S significantly increased at D7, and the levels of Mn and Fe significantly increased at R3. Meanwhile, it was observed that the roots of wheat seedlings at D7 were yellow, which might be the manifestation of root damage. Watt et al. found that the accumulation of hydrophobic substances on the cell wall of plant root epidermal cells under drought stress may affect the absorption and transmembrane transport of mineral elements in root extracellular bodies [51]. In addition, due to drought, wheat seedlings lost water and transpiration tension increased. Consequently, the transport rate was increased and the metal elements contents in the plant increased [52].It is also possible that drought stress may lead to inhibition of growth in the shoot and decrease of the pool of photo-compounds. Then the cumulative assimilate transport to the root system was increased and the root osmotic regulation was enhanced. Subsequently, 
root cells were expanded and the root system proportion were increased [53]. Ultimately, the absorption capacity of root system was enhanced and the plant metal contents were increased.

$\mathrm{Li}$ et al. reported that drought reduced Cu contents in all parts of the plant, and the greater the degree of drought, the greater the decrease. However, Mn contents in all parts increased under both drought treatment conditions, and the greater the drought degree, the more the increase [54]. Tan et al. showed that mild drought increased Cu and Mn levels in wheat seedlings, while severe drought reduced $\mathrm{Cu}$ and $\mathrm{Mn}$ contents [55]. In this study, there was no significant difference in $\mathrm{Cu}$ content in the roots at D7 under the condition of two levels of phosphorus supply. However, compared with $\mathrm{CP}$, the $\mathrm{Cu}$ content was significantly reduced in LP at R3,which indicating that LP treatment under the superimposed stress of phosphorus and drought reduced the absorption capacity of $\mathrm{Cu}$. After rehydration, the change of Mn content was just opposite to that of Cu content. LP treatment promoted the increase of Mn content, which may be related to the mechanism of $\mathrm{Mn}$ absorption by roots and the antagonism between elements. In this study, compared with D7, the contents of eight elements were significantly increased at R3 in LP, while only four elements were significantly increased under CP treatment. This indicated that LP treatment has a significantly higher recovery ability than CP after rehydration, although most element contents in LP treatment were significantly lower than that in CP. Previous studies have shown that plants deficient in phosphorus produce a series of traits similar to those adapted to water. Therefore, in the case of water stress, due to the adaptability to drought, the sensitivity to water stress is reduced, and the final result is that the yield reduction is significantly less than that of phosphorus application. Based on this, as mentioned above, the degradation level of root genomic DNA under LP treatment was significantly weaker than that under CP treatment at R3, which also confirmed that the recovery ability of LP was higher than CP treatment after rehydration, promoting the absorption and transport of related elements.

For the shoots, the contents of most elements in different comparison groups showed a downward trend, indicating that the influence of phosphorus supply and drought stress on the shoots were greater than that on the roots. In this study, it was observed that the leaves of wheat seedlings with severe drought were yellow and even dry. Phosphorus deficiency directly affects and destroys cell membrane structure, inhibits cell division, reduces chlorophyll content in leaves, and decreases photosynthesis. Compared with the elements contents at D7, seven elements in LP were significantly lower at R3, while the contents of four elements in CP increased significantly, and the difference of six elements were not significant. It was showed that drought can enhance the stress effect of low phosphorus, showing obvious superposition of stress [30-31]. However, CP treatment significantly improved the drought resistance of wheat because it satisfied the phosphorus demand of wheat. It was indicated that there are differences between the shoots and the roots in response to the stress environment.

As mentioned above, long-term phosphorus insufficient has provided wheat with certain adaptability and established a new ion balance. When water stress occurs, the ion balance is destroyed but the sensitivity is reduced. After rehydration, the content of a batch of elements, such as $\mathrm{K}, \mathrm{P}, \mathrm{Si}, \mathrm{Mn}, \mathrm{Mg}, \mathrm{Zn}, \mathrm{Ca}$ and Fe in the root, related to stress resistance increases significantly. Likewise, the contents of $\mathrm{K}$ and $\mathrm{Ca}$ in shoots increased significantly. Potassium can activate most enzymes in plant metabolism. Calcium can improve osmotic pressure of plants. The uptake and accumulation of $\mathrm{K}$ and $\mathrm{Ca}$ under water stress can reduce the adverse effects on plant growth and enhance the tolerance of plants to water stress [20]. Under two phosphorus condition, the content of silicon increased significantly at R3, which played an important role in promoting the growth of roots, improving the activity of plant roots, and promoting the absorption of water and nutrients by plants. It was worth noting that, except for the LP/CP comparison group in the root at $\mathrm{R} 3$, the content of $\mathrm{Na}$ in the other comparison groups significantly decreased. LP and CP treatments showed a decreasing trend from D7 to R3, but the decrease multiple of LP was lower than that of CP. This may be related to the increase of protons outside the root system after rehydration, which enhanced the exchange power of $\mathrm{Na}^{+}$reverse transport in the root plasma membrane, and increased the discharge of $\mathrm{Na}^{+}$in the root system 
[56].The change of Na content in LP treatment was lower than that in CP treatment. It may be related to the decrease of drought sensitivity in LP treatment.

\section{Metabolic changes in response to drought stress under two phosphorus levels}

In this study, differential metabolites in root and shoot of wheat cultured by two phosphorus levels at D3 and D7 were studied by metabonomic methods. It was found that there were significant differences in metabolites in root and shoot of wheat induced by drought stress under two phosphorus supply. As indicated above, under the supply of two levels phosphorus, drought stress had a greater influence on CP treatment than LP, among which the influences on CP shoots were greater than that on roots. While the effects of drought stress on LP roots were greater than that on shoots. Taking the ABC transporter pathway shared by LP and CP treatment groups between D3 and D7 as an example, CP treatment mainly involved sugars, especially maltose and maltodextrin. And LP mainly involved sugars were xylose, arabinose and ribose, as well as arginine. In plants, sugars are usually produced through photosynthesis, degradation of polysaccharides, and gluconeogenesis. The changes of sugar and other sugar content in plants under drought stress are considered as metabolic signals in drought-stress environment [18]. Sugar is the main participant in regulating osmotic in wheat leaves. Compared with sucrose synthesis, starch synthesis was more easily inhibited under short drought conditions. In this study, the starch and sucrose metabolic pathways in wheat roots cultured by CP between D3 and D7 were significantly changed, while no significant changes in the starch and sucrose metabolic pathways were detected under LP treatment. Likewise, we found that the amount of differential metabolites related to glucose metabolism pathways under CP treatment were higher than that of LP, further indicating that CP treatment was more sensitive to drought stress. In addition, compared with CP, LP treatment did not involve sugar metabolism at D3. While the pathways related to sugar metabolism, involving galactose metabolism, pentose and glucuronate interconversions, starch and sucrose metabolism, glycolysis/gluconeogenesis, fructose and mannose metabolism, were detected the significant difference at D7. It indicated that with the extension of drought stress period, the effect on sugar metabolism was greater. LP had the stronger adaptability to drought stress than CP, which probably is based on the comprehensive mobilization of sugar metabolism to adjust osmotic balance and cope with double stress.

Studies have shown that there are a large number of starches in plant root cap cells [57]. The starch is stable and does not hydrolyze even when the plant is hungry, but disappears under high temperature and dehydration, and the more resistant the plant is to drought, the slower the starch hydrolyzes. Therefore, the drought resistance of crop varieties can be judged by the amount of starch residue in root cap cells of seedlings after stress [57]. According to the results of gene chip in our laboratory, compared with $\mathrm{CP}$, the gene of $\beta$-amylase involved in starch degradation was significantly up-regulated. While, the genes of coding starch branching enzyme III and glycogen (starch) synthase related to starch synthesas were significantly down-regulated at D7 in LP treatment [42]. Based on this, we speculated that the degradation rate of starch was stimulated and the synthesis rate of starch decreased under LP treatment. It was consistent with the results that the fold change of glucose-1-phosphate,as the precursor of starch synthesis, was less than 1 at D7 between LP and CP group, indicating a decrease in LP (Table 4). It probably suggested that the root starch begin to degrade and the root tissue is already in a state of dehydration, which was more serious under LP than $\mathrm{CP}$ treatment. This speculation were in agreement with the performance of DNA fragmentation and root water content [42].

The metabolic analysis of bean roots showed that several sugars, including xylo-galactose, fructose, mannose and sucrose, were more plentiful in phosphorus-insufficient roots than that in phosphorus-sufficient roots, indicating that sugars may preferentially distributed in phosphorus-deficient roots to support the expression of genes induced by phosphorus stress [33]. However, in this study, compared with CP, the expression of PT1 gene (high-affinity phosphate transporter) in the roots cultured by LP was significantly down-regulated, and the gene of phosphate transporter 8 was 
significantly up-regulated at D7. Among three MYB-related protein genes induced by low phosphorus, two were downregulated and one was up-regulated [42]. In addition, most of the differential metabolites involved in sugar metabolism showed a response ratio lower than 1 , indicating a decrease in phosphorus-deficient roots (Table 4). It was inconsistent with the results of studies in soybean [33]. However, the abundance of several substances related to sugar metabolism did change. The reason for the inconsistency might be related to species and stress intensity, or it might be the different influencing mechanism of double stress of low phosphorus and drought on phosphorus absorption and sugar metabolism in this study.

Most terpenoids were involved in the differential metabolites of the shoots. Terpenoids are important secondary metabolites in plant growth and development, and they are directly or indirectly involved in a series of biological processes such as plant hormone synthesis, cell membrane stability and photosynthesis. The level of plant nutrients is involved in the regulation of terpene metabolism [58]. The changes of terpenoids contribute to the self-protection and defensive response of plants. In this study, the contents of relevant terpenoids in the shoots treated by CP at D3 were significantly higher than that at D7. In addition, terpenoids were more involved in shoot differential metabolites than roots, indicating that drought stress under CP treatment had a greater influence on terpenoids synthesis in shoots than roots and were more affected by early drought.

Our metabolic analysis of wheat phosphorus-sufficient shoots indicated the osmotic regulation of short-term drought (drought for 3d) may be due to the greater effect of free amino acids and prolines than soluble sugars

(Supplementary table 1). With the extension of drought stress period, photosynthesis decreased, amino acid synthesis and proline metabolism decreased, sugar metabolism and organic acid increased, at this moment, the osmotic regulation of soluble sugar may be stronger than that of proline (Supplementary table 1). Additionally, our ion contents analysis revealed that the content of cations such as $\mathrm{K}^{+}, \mathrm{Ca}^{2+}$ and $\mathrm{Na}^{+}$in the shoots treated by $\mathrm{CP}$ was significantly higher than that of LP at D7. Previous studies have shown that the accumulation of organic acids in vacuoles may play a central role in the regulation of intracellular $\mathrm{pH}$ by neutralizing excess cations [61, 62].Therefore, it is necessary to accumulate various organic acids in plant cells, which is also the key adaptation mechanism to maintain intracellular ion homeostasis in seedlings under stress. These information investigated that the various osmotic regulatory substances play different roles during different drought periods. While, due to the decrease of sensitivity to drought, the changes of each osmotic regulatory substance in the shoots were not obvious under LP treatment.

\section{Conclusion}

Through drought stress and rehydration treatment subjected to wheat seedlings, it was found that the wheat plants under the low phosphorus treatment was more adaptable to drought stress and recovered faster after rehydration. The following viewpoints from this work provide well explanation for the adaptation mechanism of wheat to drought stress under sufficient and insufficient phosphorus supply. (i) The wheat plants subjected to LP treatment had denser root system, and the total root volume was significantly higher than CP treatment. (ii) The phenomenon of root tip enlargement and the changes of related metabolites suggested that the polyploidy of root cells decreased under LP treatment, which was conducive to the effective utilization of water and mineral nutrients. (iii) The analysis of mineral elements and metabolites showed that CP treatment was more sensitive to drought stress, and drought stress had more influence on the shoots of CP treatment than the roots. While the effects of drought stress on LP roots were greater than that on shoots. With the extension of drought stress, the effect on sugar metabolism was greater. In summary, the wheat plants under LP treatment was more adaptive to drought stress than that in CP treatment, which probably is based on the comprehensive mobilization of sugar metabolism to regulate osmotic balance. Meanwhile, the accumulation of various organic acids maintains the intracellular ion homeostasis. These newly identified

Page 15/24 
viewpoints may be of utility in further explore the important role of phosphorus in adaptation of wheat plants to drought stress.

\section{Abbreviations}

CP: conventional phosphorus; LP: low phosphorus; D3: drought stress for 3 days; D7: drought stress for 7 days; R3: rehydration for 3 days

\section{Declarations}

\section{Ethics approval and consent to participate}

Not applicable.

\section{Consent for publication}

Not applicable.

\section{Availability of data and materials}

Metabolite pathways were searched on KEGG (http://www.genome.jp/kegg/). Further data analysis was conducted by using the MetaboAnalyst website (www.metaboanalyst.ca/). The datasets during or analyzed during this study available from the corresponding author on reasonable request.

\section{Competing interests}

The authors declare that they have no competing interests.

\section{Funding}

The funders had no role in the experiment design, data analysis, decision to publish or preparation of the manuscript. This research was financially supported by the project of National Natural Science Foundation of China (No. 31860337; 31860335; 31360292; 31560389); Young Innovator Cultivating Project of Shihezi University (No. CXRC201703); New Cultivar Breeding and Germplasm Enhancement of Wheat (No. 2016AC027); and Specific Project for Breeding of Shihezi University (No. YZZX202002).

\section{Authors' contributions}

Li Chunyan, Li Cheng and Zhang Xiangchi: designed the study and wrote the manuscript. Li Chao and Wan Wen: performed the experiments and analyzed the data. All authors read and approved the final manuscript.

\section{Acknowledgements}

All authors are grateful to BGI Genomics Co., Ltd in China for providing helps in data measure and analysis.

\section{Authors' Information}

College of Agriculture/The Key Laboratory of Oasis Eco-agriculture, Xinjiang Production and Construction Group, Shihezi University, Shihezi, Xinjiang 832000, P.R. China 


\section{References}

1. Zhang LG, Deng XP. Advances in studies on physiology and biochemistry of wheat drought resistance. Agric Res Arid Areas. 2000; 18(3):87-92.

2. Su JY, Zheng Q, Li HW, Li B, Jing RL, Tong YP, Li ZS. Detection of QTLs for phosphorus use efficiency in relation to agronomic performance of wheat grown under phosphorus sufficient and limited conditions. Plant Sci. 2009; 176(6):824-836.

3. Batten GD. A review of phosphorus efficiency in wheat. Plant Soil. 1992; 146(1):163-168.

4. Hirel B, Gouis JL, Ney B, Gallais A. The challenge of improving nitrogen use efficiency in crop plants: towards a more central role for genetic variability and quantitative genetics within integrated approaches. J Exp Bot. 2007; 58: 2369-2387.

5. He JF, Ravinder G, Laroche A, Zhao ML, Lu ZX. Water stress during grain development affects starch synthesis, composition and physicochemical properties in triticale. J Cereal Sci. 2012; 56: 552-560.

6. Fabian A, Jager K, Rakszegi M, Barnabas B. Embryo and endosperm development in wheat (Triticum aestivum L.) kernels subjected to drought stress. Plant Cell Rep. 2011; 30: 551-563.

7. Raghothama KG. Phosphate acquisition. Annu Rev Plant Physiol. Plant Mol Biol. 1999; 50: 665-693.

8. Smith FW. Sulphur and phosphorus transport systems in plants. Plant Soil. 2001;232: 109-118

9. Vance CP, Uhde SC, Allan DL. Phosphorus acquisition and use: critical adaptations by plants for securing a nonrenewable resource. New Phytol. 2010; 157: 423-447.

10. Plaxton WC. Plant responses to stress: biochemical adaptations to phosphate deficiency. In RM Goodman, ed, Encyclopedia of Plant and Crop Science. Marcel Dekker, New York, 2004, pp 976-980.

11. Rodriguez D, Goudriaan J. Effects of phosphorus and drought stresses on dry matter and phosphorus allocation in wheat. J. Plant Nutrition, 1995; 18(11):2501-2517.

12. Zhang SG, Liu GD, Dou YQ, Liu GL. Effects of low-phosphorus and drought stresses on growth of wheat (Triticum aestivum). Acta Bot. Boreali-occident. Sin. 2002; 22(3):574-578.

13. Mcbeath TM, Mclaughlin MJ, Kirby JK, Armstrong RD. The effect of soil water status on fertiliser, topsoil and subsoil phosphorus utilisation by wheat. Plant Soil, 2012; 358(1-2):337-348.

14. Schauer N, Fernie AR. Plant metabolomics: towards biological function and mechanism. Trends Plant Sci. 2006; $11,508-516$.

15. Wu D, Shen Q, Cai S, Chen ZH, Fei D, Zhang G. lonomic responses and correlations between elements and metabolites under salt stress in wild and cultivated barley. Plant Cell Physiol. 2013; 54:1976-1988.

16. Kobayashi F, Takumi S, Nakata M, Ohno R, Nakamura C. Comparative study of the expression profiles of the Cor/ Lea gene family in two wheat cultivars with contrasting levels of freezing tolerance. Physiol Plantarum. 2010; 120(4):585-594.

17. Allwood JW, Chandra S, Xu Y, Dunn WB, Correa E, Hopkins L, Goodacre R, Tobin AK, Bowsher CG. Profiling of spatial metabolite distributions in wheat leaves under normal and nitrate limiting conditions. Phytochemistry. 2015; 115(1):99-111.

18. Roessner U. Drought responses of leaf tissues from wheat cultivars of differing drought tolerance at the metabolite level. Mol. Plant. 2012; 5(2):418429.

19. Spickett CM, Smirnoff N, Ratcliffe RG. Metabolic response of maize roots to hyperosmotic shock: An in vivoP nuclear magnetic resonance study. Plant Physiol.1992; 99(3):856-863. 
20. Hare PD, Cress WA, Staden JV. Dissecting the roles of osmolyte accumulation during stress. Plant Cell Environ. 2010; 21(6):535-553.

21. Dennison KL, Robertson WR, Lewis BD, Hirsch RE, Spalding EP. Functions of AKT1and AKT2 potassium channels determined by studies of single and double mutants of Arabidopsis. Plant Physiol. 2001; 127(3):1012-1019.

22. Chen THH, Murata N. 2002. Enhancement of tolerance of abiotic stress by metabolic engineering of betaines and other compatible solutes. Curr Opin Plant Biol. 2002; 5(3)5:250-257.

23. Yasar F, Uzal O, Tufenkci S, Yildiz K. Ion accumulation in different organs of green bean genotypes grown under salt stress. Plant Soil Environ. 2006; 52:476-480.

24. Wang H, Zhang M, Guo R, Shi D, Liu B, Lin X, Yang C. Effects of salt stress on ion balance and nitrogen metabolism of old and young leaves in rice (Oryza sativa L.). BMC Plant Biol. 2012; 12(1):194.

25. Selote DS, Bharti S, Chopra RK. Drought treatement reduces $\mathrm{O}_{2}$-accumulation and lipid peroxidation in wheat seedlings. Biochem. Bioph. Res. Co. 2004; 314:724-729.

26. Curie C, Briat J F. Iron transport and signaling in plants. Annu Rev Plant Biol. 2003; 54(1):183-206.

27. Zhang GW. Study on the physiological mechanism of soil salinity affecting the growth of cotton (Gossypium hirsutum L.) $₫$ Nanjing: Nanjing Agric.Univ.2011区

28. Hou PC, Wang XD, Hou RF, Yu CH, Sun J, Lou XL, Wei ZZ, Wang C. The relationship between primary root hair development and net $\mathrm{K}^{+}$flux in drought resist and drought sensitive wheat. Proc. 2010 First Int Con Cell Mol Biol Bio Bioe. (Volume 7).

29. Sadiqov ST, Akbulut M, Ehmedov V. Role of $\mathrm{Ca}^{2+}$ in drought stress signaling in wheat seedlings. Biochemistry, 2002, 67(4):491-497.

30. Zhang SQ, Shan L. The effect of phosphorus nutrition on drought-resistance of spring wheat. Chinese J. Appl. Environ. Biol. 1998; 2:115-119.

31. Zhang SQ, Shan L. The effects of phosphorus nutrition and water stress on yield and water use efficiency of spring wheat. Acta Agric. Boreali-occidentalis Sin.1997; 1:22-25.

32. Li WC. Effect of water, $\mathrm{N}$ and $\mathrm{P}$ coupling on root physiological and anatomical features of winter wheat. Yangling: Northwest A \& F Univ. 2012.

33. Hernandez G, Ramirez M, Valdes-Lopez O, Tesfaye M, Graham MA, Czechowski T , Schlereth A囚Wandrey MヌErban A囚Cheung F . Phosphorus stress in common bean: root transcript and metabolic responses. Plant Physiol. 2007; 144(2):752-767.

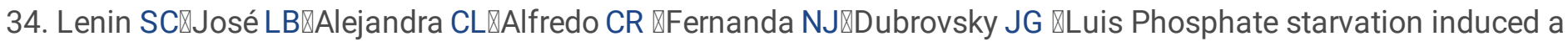
determinate development program in roots of Arabidopsis thaliana. Plant Cell Physiol. 2005; 46(1): 174-184.

35. Beebe SE, Rojas-Pierce M, Yan X, Blair MW, Garcia FP, Munoz F, Tohme J, Lynch JP. Quantitative trait loci for root architecture traits correlate with phosphorus acquisition in common bean. Crop Sci. 2006; 46(1): 413-423.

36. Gilbert GA, Knight JD, Vance CP, Allan DL. Proteoid root development of phosphorus deficient lupin is mimicked by auxin and phosphonate. Ann Bot. 2000; 85(6): 921-928.

37. Williamson LC, Ribrioux SPCP, Fitter AH, Leyser HMO. Phosphate availability regulates root system architecture in Arabidopsis. Plant Physiol. 2001; 126: 875-882.

38. Al-Ghazi Y, Muller B, Pinloche S, Tranbarger TJ, Nacry P, Rossignol M, Tardieu F, Doumas P. Temporal responses of Arabidopsis root architecture to phosphate starvation: evidence for the involvement of auxin signaling. Plant Cell Environ. 2003; 26(7): 1053-1066. 
39. Lo'pez-Bucio J, Cruz-Ramı́rez A, Herrera-Estrella L. The role of nutrient availability in regulating root architecture. Curr Opin Plant Biol. 2003; 6(3): 280-287.

40. Ma Z, Baskin TI, Brown KM, Lynch JP. Regulation of root elongation under phosphorus stress involves changes in ethylene responsiveness. Plant Physiol. 2003; 131: 1381-1390.

41. Karthikeyan AS, Varadarajan DK, Jain A, Held MA, Carpita NC, Raghothama KG. Phosphate starvation responses are mediated by sugar signaling in Arabidopsis. Planta. 2006; 225: 907-918.

42. Zhang XC, Lu WD, Wang XL, Ma B, Fu KY, Li CY, Li C. Comparative analysis of combined phosphorus and drought stress-responses in two winter wheat. AOB plants. Peer review.

43. Wilson C, Pfosser M, Jonak C, Hirt H, Hbberle-Bors EF, Vicente O. Evidence for the activation of a MAP kinase upon phosphate-induced cell cycle re-entry in tobacco cells. Physiologia Plantarum, 2010; 102(4):532-538.

44. Stals H, Inzé D. When plant cells decide to divide. Trends. Plant Sci.2001; 6(8):359-364.

45. Zeng Z, Huang H, Han N, Huang CY, Zhu M. Endopolyploidy levels in barley vary in different root types and significantly decrease under phosphorus deficiency. Plant Phy Bioc. 2017; 118, 11-21.

46. Riou-Khamlichi C, Menges M, Healy JMS, Murray JAH. Sugar control of the plant cell cycle: differential regulation of arabidopsis d-type cyclin gene expression. Mol Cell Bio. 2000; 20(13), 4513-4521.

47. Cookson SJ, Radziejwoski A, Granier C. Cell and leaf size plasticity in Arabidopsis: what is the role of endoreduplication? Plant Cell Environ. 2006; 29, 1273-1283.

48. Hermans C, Hammond JP, White PJ, Verbruggen N. How do plants respond to nutrient shortage by biomass allocation? Trends Plant Sci. 2006; 11,610-617.

49. Schachtman DP, Reid RJ, Ayling SM. Phosphorus uptake by plants: from soil to cell. Plant Physiol. 1998; 116, 447-453.

50. lii FSC, Bieleski RL. Mild phosphorus stress in barley and a related low-phosphorus-adapted barley grass: Phosphorus fractions and phosphate absorption in relation to growth. Physiologia Plantarum. 2010; 54(3):309317.

51. Watt M, Weele CMVD, Mccully ME, Canny MJ. Effects of local variations in soil moisture on hydrophobic deposits and dye diffusion in corn roots. Bot Acta. 1996; 109(6):492-501.

52. Gong JM, Lee DA, Schroeder JI. Long-distance root-to-shoot transport of phytochelatins and cadmium in Arabidopsis. Proc Natl Acad Sci USA. 2003; 100(17):10118-10123.

53. Wang H, Wang LG, Zhou W, Jin JY. Soil zinc availability under water stress condition and its relationship with plant water utilization, Plant Nutri Fertilizer. 2007; 6: 1178-1184.

54. Liu ST, Dong XW, Sun CH, Wei ZG, Wang WH. Effect of water stress on growth development and yield of summer corn. J. Laiyang Agric. College.2003; 20(2):98-100.

55. Tan XR, DaiY, Fu Y. Effect of drought on content of copper and manganese in wheat seedlings and related mechanism. Agric. Research. Arid Areas, 2010, 28(1):152-159.

56. Yang CW, Shi DC, Wang DL. Comparative effects of salt stress and alkali stress on growth, osmotic adjustment and ionic balance of an alkali resistant halophyte Suaeda glauca (Bge). Plant Growth Regula.2008; 56:79-190.

57. Peng T, Wang W, Cui DC, Li DQ. Osmotic Adjustment in wheat roots and hydrolysis of starch in root-cap of wheat under osmotic stress. Acta Bot Boreali-Occiden. Sin. 2005; 25(2):218-224.

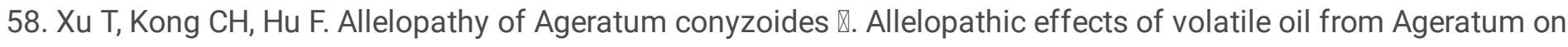
plants under different nutrient levels. Chinese J. Appl. Ecology, 1999; 10(6):748-750. 
59. Dicke M. Local and systemic production of volatile herbivore-induced inducedterpenoids: their role in plantherbivore mutualism. Plant Physiol, 1994; 143: 465-472.

60. Shen B, Zheng Z, Dooner HK. A maize sesquiterpene cyclase gene induced by insect herbivory and volicitin: characterization of wild-type and mutant alleles. Proc Natl Acad Sci USA, 2000, 97(26):14808-14812.

61. Yang C, Xu HH, Wang L, Liu J, Shi DC, Wang D. Comparative effects of salt stress and alkaline-stress on the growth, photosynthesis, solute accumulation, and ion balance of barley plants. Photosynthetica. 2009; 47:79-86.

62. Wang H, Ahan J, Wu ZH, Shi DC, Liu B, Yang CW. Alteration of nitrogen metabolism in rice variety 'Nipponbare' induced by alkali stress. Plant Soil.2012; 355:131-47.

\section{Figures}

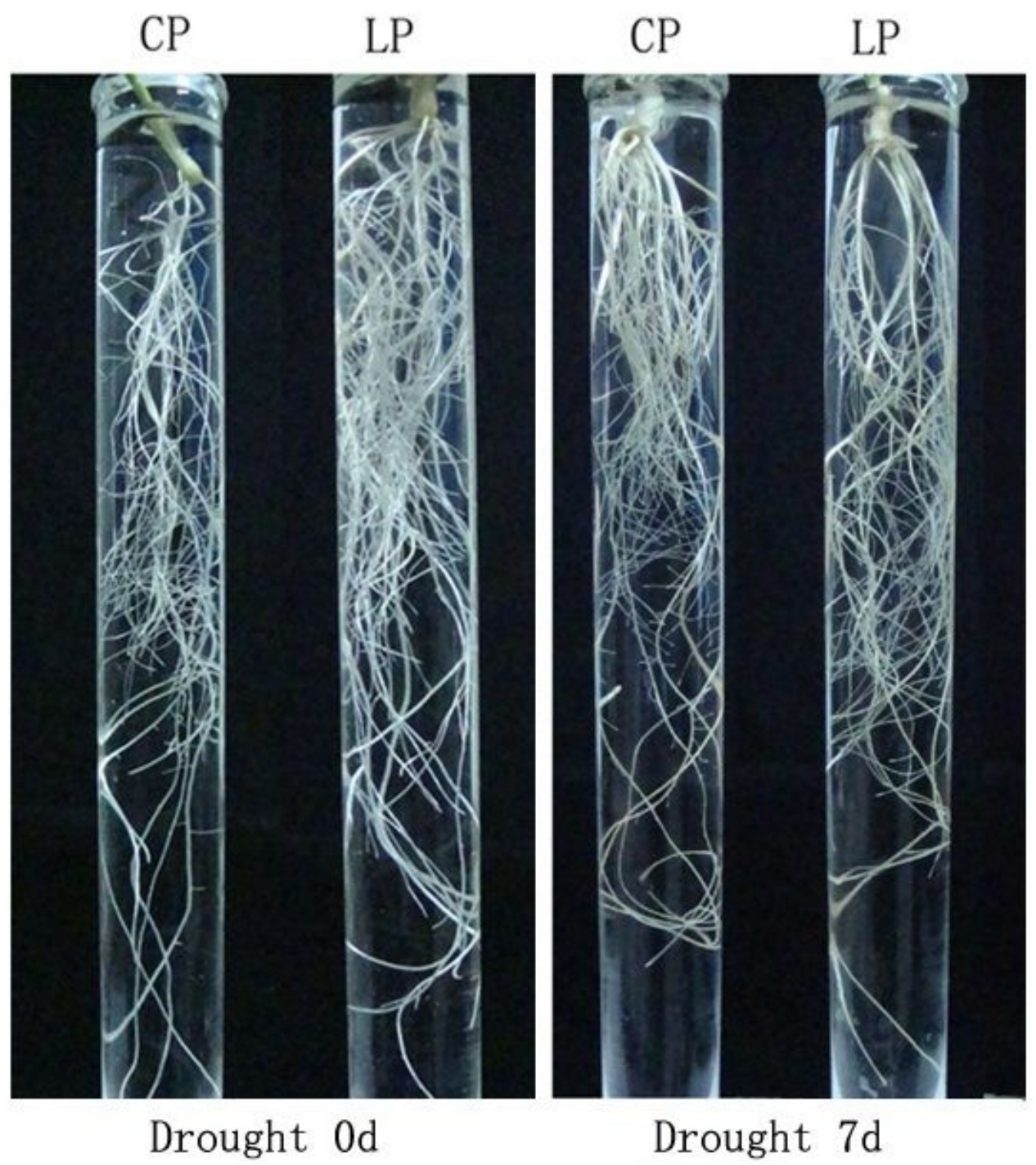

\section{Figure 1}

The morphology of wheat roots cultured by CP and LP under drought stress. 

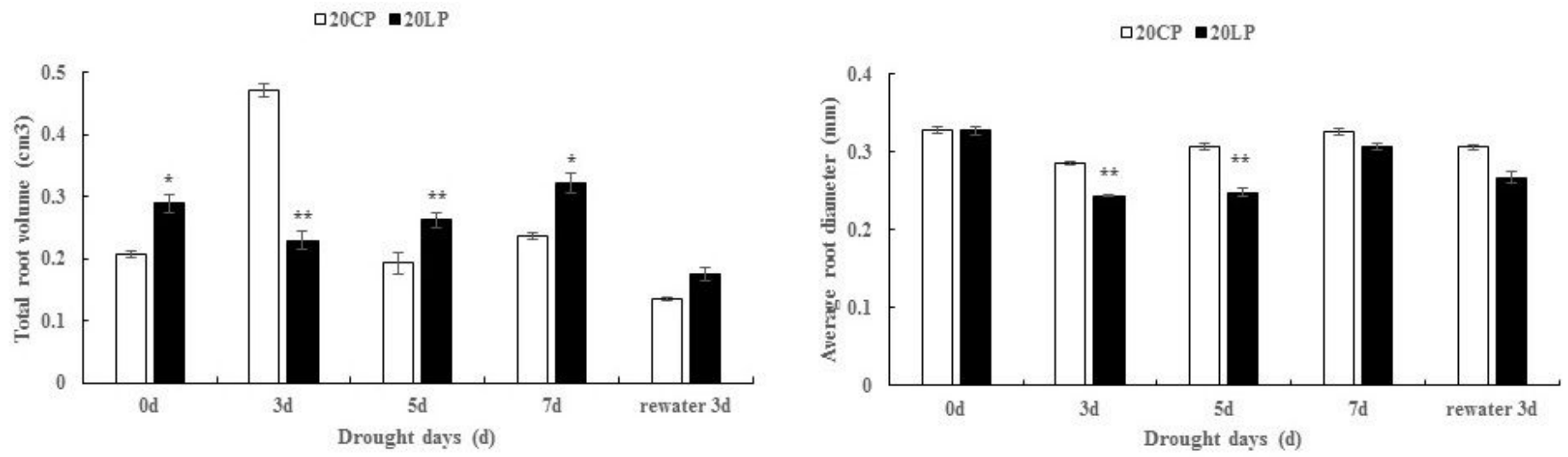

Figure 2

The total volume and average diameter of wheat roots. 
口20CP -20LP
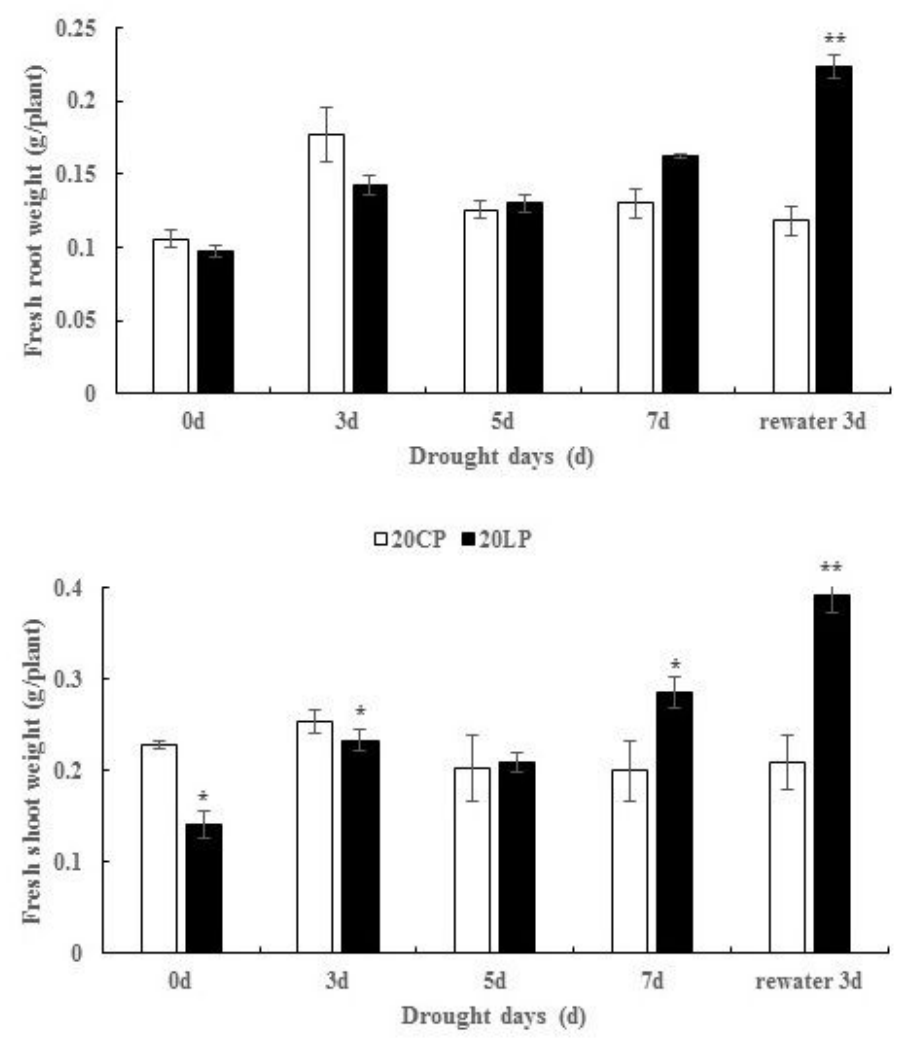

$\square 20 \mathrm{CP} 20 \mathrm{LP}$

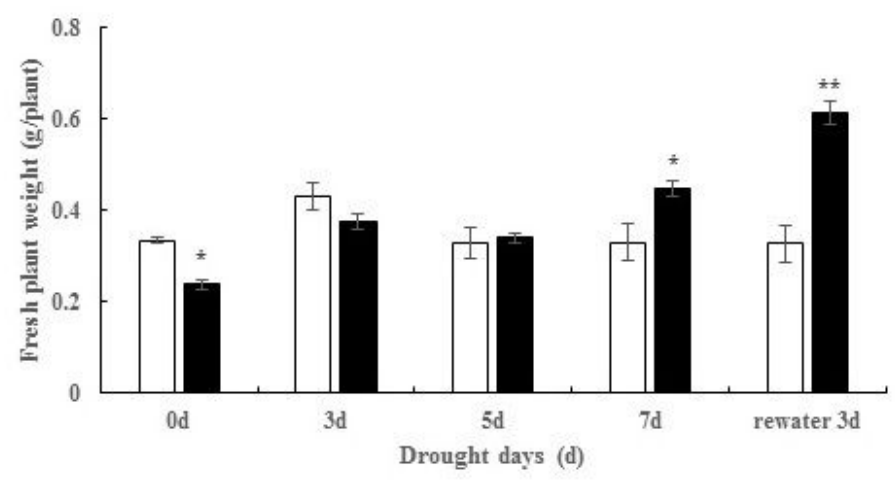

口20CP 20LP

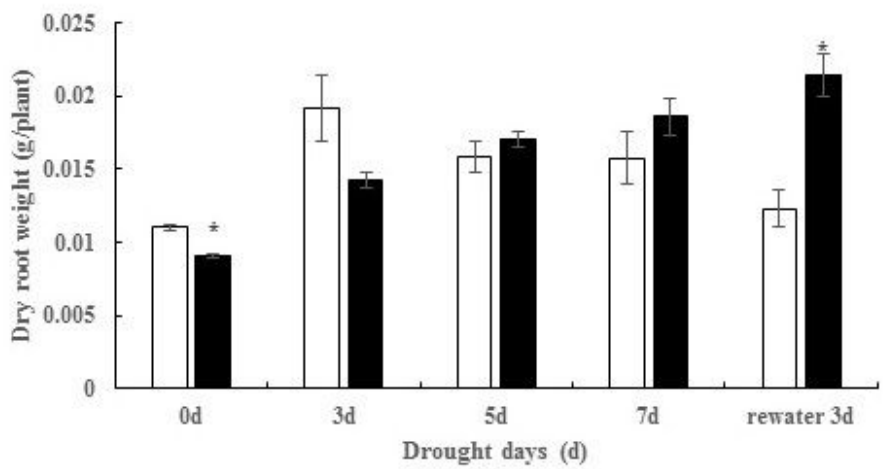

口20CP $\mathbf{2} 20 \mathrm{LP}$

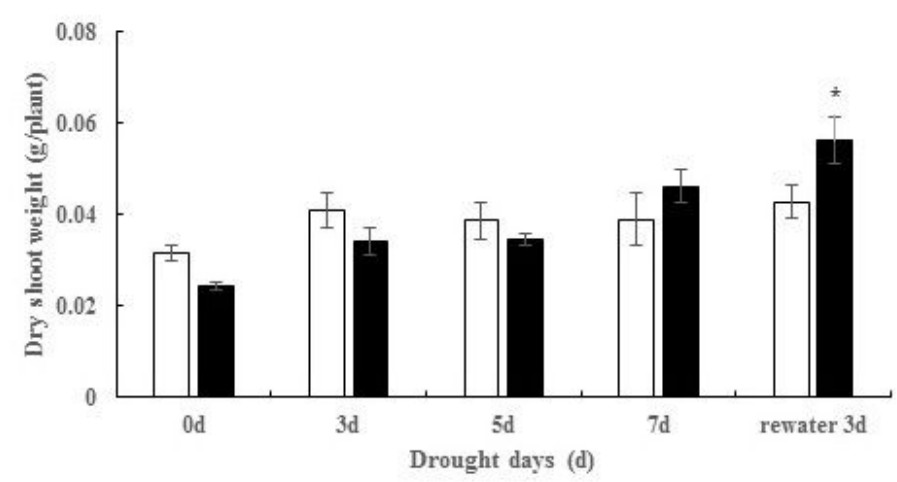

口20CP $20 \mathrm{LP}$

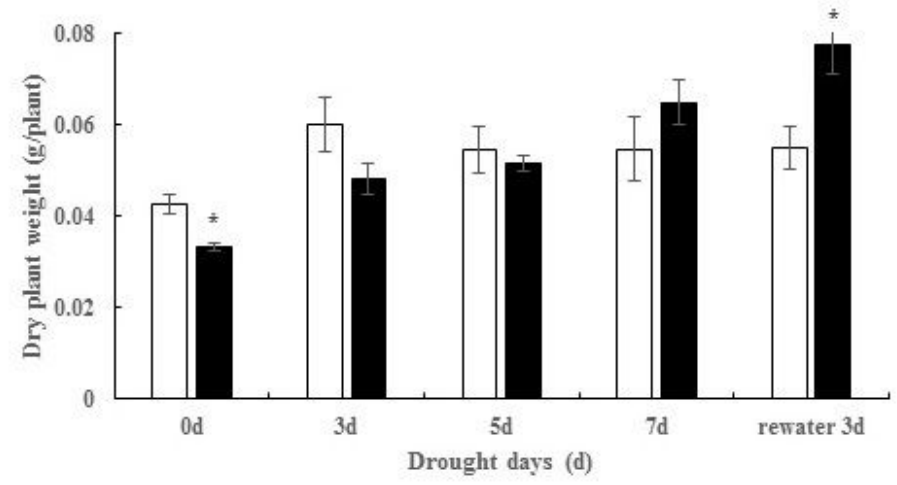

Figure 3

The fresh and dry weight of wheat plants. 


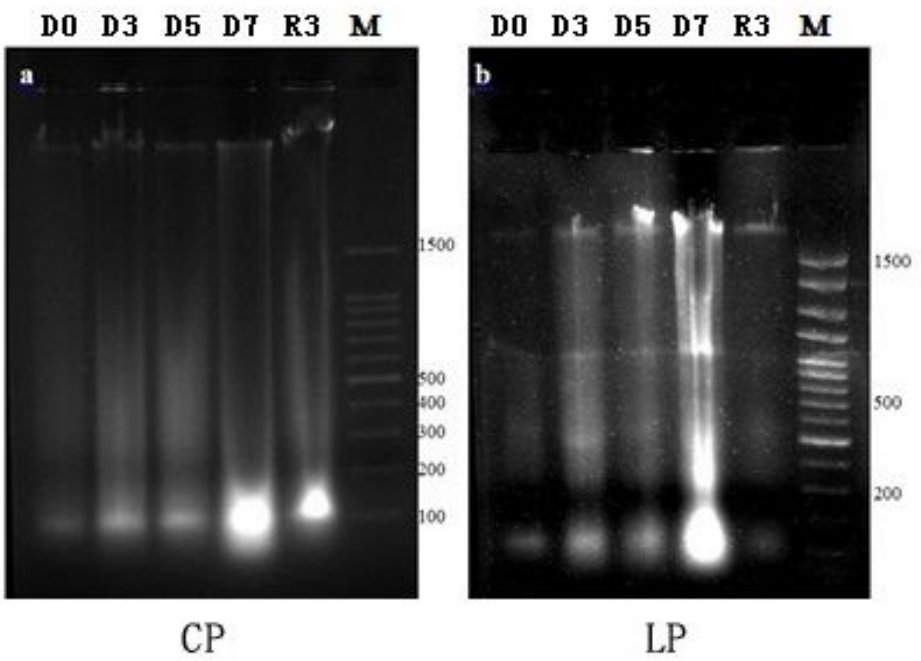

\section{Figure 4}

DNA fragmentation analysis. Note: CP refers conventional phosphorus. LP refers low phosphorus. D0, D3, D5 and D7 refer drought stress for $0,3,5,7$ days, respectively. R3 refers rehydration for 3 days. M refers marker. 


\begin{tabular}{|l|l|l|l|}
\hline LP-D7/CP-D7 & LP-R3/CP-R3 & LP-R3/LP-D7 & CP-R3/CP-D7 \\
\hline
\end{tabular}

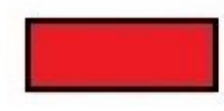

Increased

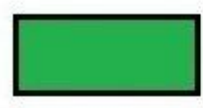

Decreased

No significant change
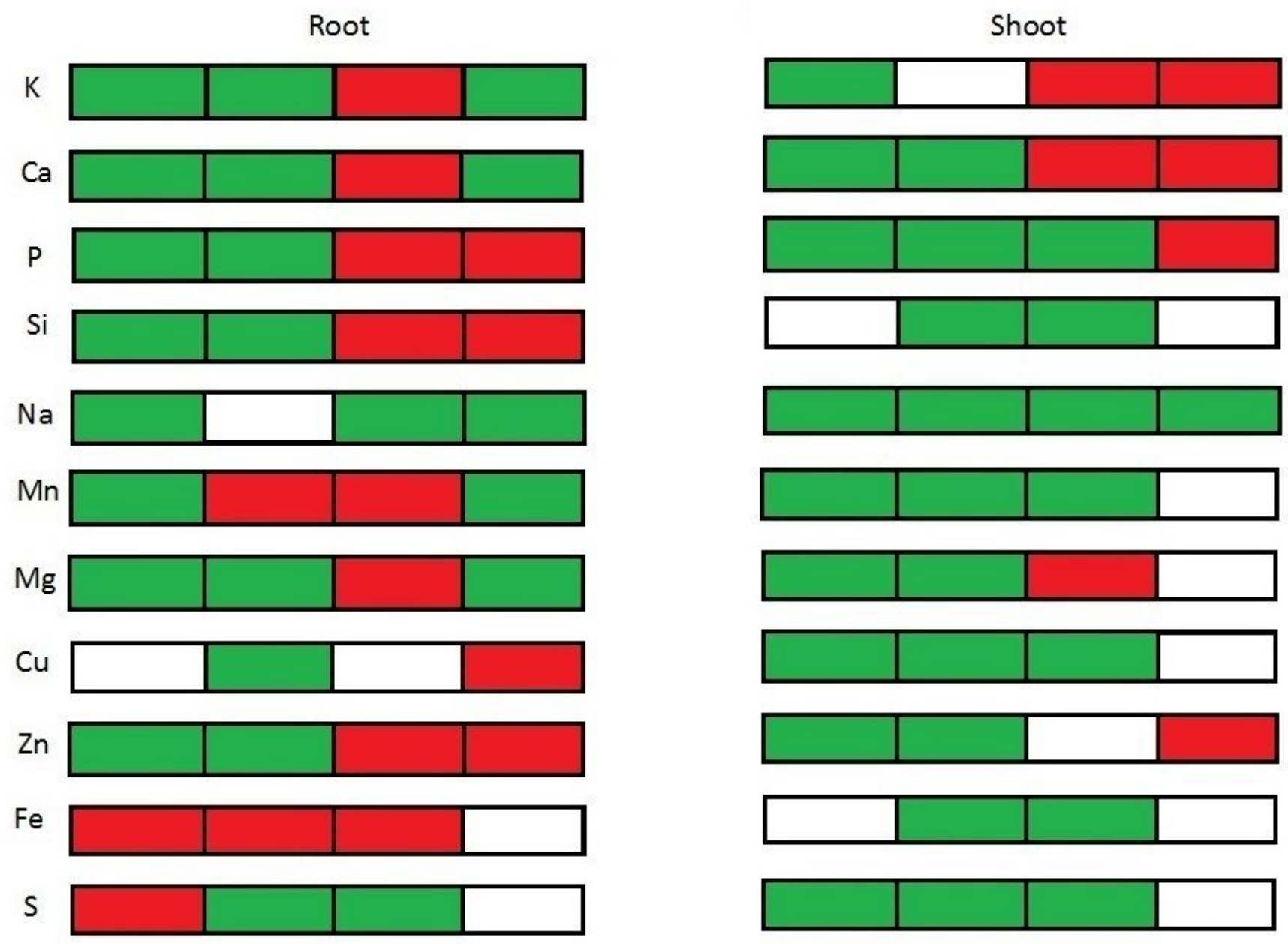

\section{Figure 5}

The changes of mineral elements in the roots and shoots. Note: Red boxes refer to significantly enhanced elements, whereas those in green boxes were significantly reduced $(P<0.05)$. CP: conventional phosphorus; LP: low phosphorus; D3: drought stress for 3 days; D7: drought stress for 7 days; R3: rehydration for 3 days

\section{Supplementary Files}

This is a list of supplementary files associated with this preprint. Click to download.

- DNAladder.doc

- Supplementarytables.docx 